\title{
Synthesis of ceramic superconductors under low oxygen pressure
}

\author{
U BALACHANDRAN, R B POEPPEL, J E EMERSON, \\ M T LANAGAN, C A YOUNGDAHL/and S A JOHNSON ${ }^{\dagger}$ \\ Materials and Components Technology Division, ${ }^{\dagger}$ Chemical Technology Division, Argonne \\ National Laboratory, Argonne. Illinois 60439, USA
}

\begin{abstract}
We have developed a process for synthesizing orthorhombic $\mathrm{YBa}_{2} \mathrm{Cu}_{3} \mathrm{O}_{x}(123)$ superconducting powders by calcination of the precursor powder under reduced total oxygen pressure. Because a single calcination at $800^{\circ} \mathrm{C}$ for $4 \mathrm{~h}$ in flowing oxygen at a pressure of $2 \mathrm{~mm}$ $\mathrm{Hg}$ results in essentially phase-pure material, total calcination times have been drastically reduced. At liquid nitrogen temperature, sintered pellets made from this powder have critical current densities of $\sim 1000 \mathrm{~A} / \mathrm{cm}^{2}$ in zero applied magnetic field.
\end{abstract}

Keywords. Synthesis: improved calcination; ceramic superconductors.

\section{Introduction}

High-temperature ceramic superconductors are normally prepared via solid-state reaction from a mixture of precursors such as oxides, carbonates, and/or nitrates. The mixed precursors are calcined at $900-950^{\circ} \mathrm{C}$ for $50-100 \mathrm{~h}$ with intermittent grindings (Goretta et al 1988). The high calcination temperatures used in this conventional method result in the formation of liquid phases and some nonsuperconducting phases such as $\mathrm{Y}_{2} \mathrm{BaCuO}_{5}$ and $\mathrm{BaCuO}_{2}$. Also, the $\mathrm{CO}_{2}$ released by decomposition of $\mathrm{BaCO}_{3}$ can react with 123 to form $\mathrm{BaCO}_{3}, \mathrm{Y}_{2} \mathrm{O}_{3}, \mathrm{CuO}$ and $\mathrm{Y}_{2} \mathrm{Cu}_{2} \mathrm{O}_{5}$, depending on temperature (Fjellvag et al 1988). The presence of these nonsuperconducting phases, especially at grain boundaries, lowers critical current density (Shi et al 1988). In addition, the conventional process is very time-consuming and results in coarse particles. Partial vacuums have been utilized by other investigators to calcine powders and to sinter polycrystalline bodies (Uno et al 1988; Lay 1989); in all cases, however, multiphase materials were obtained. We report here a synthesis route to obtain essentially phase-pure orthorhombic 123 powders at $800^{\circ} \mathrm{C}$ in flowing $\mathrm{O}_{2}$ at reduced pressure.

\section{Experimental methods}

Required amounts of $\mathrm{Y}_{2} \mathrm{O}_{3}, \mathrm{BaCO}_{3}$ and $\mathrm{CuO}$ were wet-milled for about $15 \mathrm{~h}$ in methanol. The resultant slurry was pan-dried in air, ground in an agate mortar and heated at $\sim 20^{\circ} \mathrm{C} / \mathrm{h}$ in the temperature range of $700-800^{\circ} \mathrm{C}$ in flowing $\mathrm{O}_{2}$ at a pressure of $2 \mathrm{~mm} \mathrm{Hg}$ and held for $4 \mathrm{~h}$ at $800^{\circ} \mathrm{C}$. During cooling, the vacuum was discontinued and ambient-pressure $\mathrm{O}_{2}$ was passed. A 3-h hold at $450^{\circ} \mathrm{C}$ was incorporated into the cooling schedule to promote oxygenation of the resulting powder. A Fouriertransform infrared (FTIR) spectrometer was used to monitor $\mathrm{CO}_{2}$ evolution during calcination. Heating and $\mathrm{O}_{2}$ flow rates were adjusted to maintain various levels of $\mathrm{CO}_{2}$ during calcination. The calcined powders were characterized by thermal analyses and X-ray diffraction. 


\section{Results and discussion}

Thermogravimetric analysis (TGA) showed that during heating of the precursor powders at the ambient pressure of one atmosphere, the weight loss attributable to $\mathrm{CO}_{2}$ evolution begins at about $750^{\circ} \mathrm{C}$; however, at $2 \mathrm{~mm} \mathrm{Hg}$, it begins at $620^{\circ} \mathrm{C}$. Under reduced total pressure, decomposition is essentially complete at $\sim 800^{\circ} \mathrm{C}$, whereas under ambient pressure, decomposition is not complete even at $\sim 1000^{\circ} \mathrm{C}$. Heating of powders at $\sim 20^{\circ} \mathrm{C} / \mathrm{h}$ in the range of $700-800^{\circ} \mathrm{C}$ maintained $\mathrm{CO}_{2}$ levels - as measured by FTIR - at less than $2 \%$ of the oxygen level. At $900^{\circ} \mathrm{C}$ under ambient pressure, the calculated thermodynamic equilibrium partial pressure of $\mathrm{CO}_{2}$ at which 123 becomes unstable is $\sim 2 \%$ in the oxygen atmosphere (Fjellvag et al 1988). Faster heating rates resulted in higher $\mathrm{CO}_{2}$ concentrations and yielded powders containing $\mathrm{Y}_{2} \mathrm{BaCuO}_{5}$ and other impurity phases. Endothermic or exothermic reactions or melting events associated with impurity phases were identified by differential thermal analysis (Goretta et al 1988). As shown in figure 1, for the powder calcined once at $800^{\circ} \mathrm{C}$ in low pressure, the only observed event was a change in slope caused by conversion of the powder from orthorhombic to tetragonal upon heating (curve a). Conventionally processed powder (calcined three times at $900^{\circ} \mathrm{C}$ under ambient pressure) exhibited an endotherm at $\sim 940^{\circ} \mathrm{C}$ caused by melting of a CuO- $\mathrm{BaCuO}_{2}$ eutectic (curve b). These traces were obtained in flowing oxygen at ambient pressure.

The 123 powder processed at low pressure was also shown to be phase-pure by $\mathrm{X}$-ray diffraction (figure 2). Analysis of the orthorhombic-peak split and comparison against published data (Wong- $\mathrm{Ng}$ et al 1987) revealed no tetragonal phase in the powder. Particle size resulting from the low-pressure synthesis was 1 to $4 \mu \mathrm{m}$. This relatively small particle size is due to the low processing temperature. Calcination could be carried out at $800^{\circ} \mathrm{C}$, rather than $900^{\circ} \mathrm{C}$ or higher, because cation diffusional kinetics in 123 are faster under reduced $\mathrm{O}_{2}$ pressures (von Stumberg et al 1989). A partial vacuum was used instead of a mixture of $\mathrm{O}_{2}$ and a noble gas because $\mathrm{CO}_{2}$ was removed with increased efficiency.

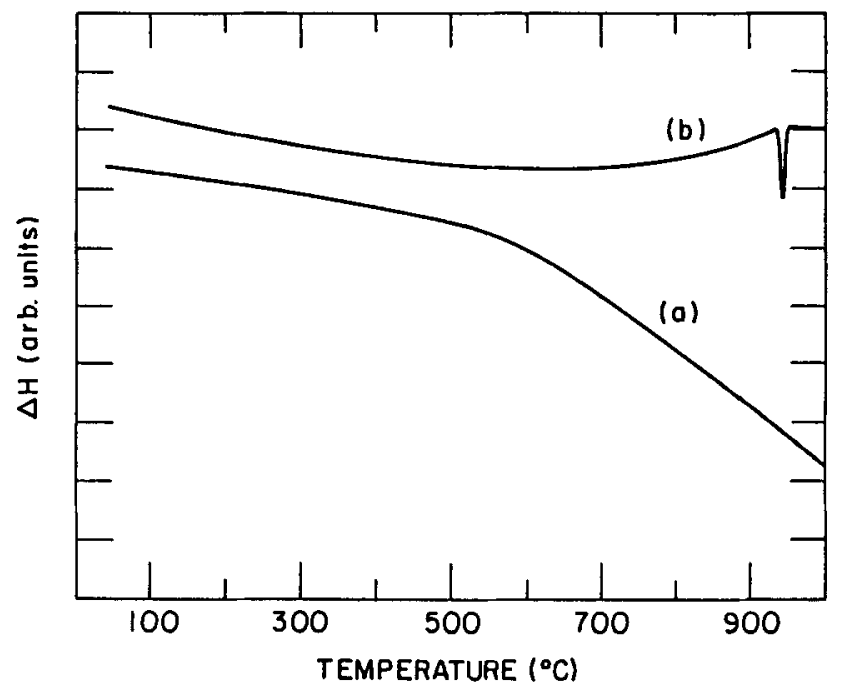

Figure 1. Differential thermal analysis traces of 123 powder calcined at (a) $2 \mathrm{mmHg}$ pressure and (b) ambient pressure. 


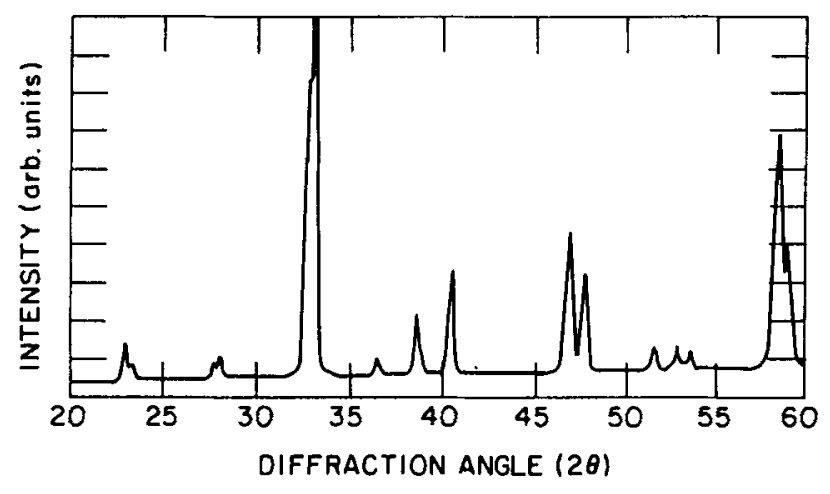

Figure 2. X-ray diffraction pattern of 123 powder prepared by low-pressure calcination.

The resultant 123 powder was cold-pressed into pellets that were capable of levitating magnets. These pellets were then sintered in $\mathrm{O}_{2}$ to make dense superconductors. For sintering at 915 to $980^{\circ} \mathrm{C}$, pellet densities ranged from 90 to $96_{\%}^{\circ}$ of theoretical, and similar superconducting properties were achieved. Critical current densities, measured in zero applied magnetic field at $77 \mathrm{~K}$ with a criterion of $1 \mu \mathrm{V} / \mathrm{cm}$, were about $1000 \mathrm{~A} / \mathrm{cm}^{2}$, whereas samples prepared by the ambient-pressure method attain a value of only about $300 \mathrm{~A} / \mathrm{cm}^{2}$.

\section{Conclusions}

Solid-state reaction remains the simplest technique for synthesizing 123 superconductors. Use of $\mathrm{BaCO}_{3}$, which is not hygroscopic, obviates the need for processing in carefully controlled humidity. A single calcination at $800^{\circ} \mathrm{C}$ for $4 \mathrm{~h}$ in reduced total oxygen pressure gives essentially phase-pure, orthorhombic 123 powders. The reaction temperature is about $100-150^{\circ} \mathrm{C}$ lower than that used in ambient-pressure calcination, and the lower temperature results in finer particles. The powder production rate depends on the capacities of vacuum pumps and furnace reaction chambers; because both of these can be large, the process described here can produce many kilograms of phase-pure, orthorhombic 123 per day.

\section{Acknowledgements}

The authors thank Donglu Shi and Ming Xu for measuring superconducting properties. This work was supported by the U.S. Department of Energy, Office of Energy Storage and Distribution, Conservation and Renewable Energy, under Contract W-31-109-Eng-38.

\section{References}

Fjellvag P, Karen P, Kjekshus A, Kofstad P and Norby T 1988 Acta Chem. Scand. A42 178 Goretta K C et al 1988 Mater. Lett. 7161 
Lay K W 1989 J. Am. Ceram. Soc. 72696

Shi D, Capone II D W, Goudey G T, Singh J P, Zaluzec N J and Goretta K C 1988 Mater. Lett. 6217

Uno N, Enomoto N, Tanaka Y and Takami H 1988 Jpn. J. Appl. Phys. 27 L1003

von Stumberg A W, Chen N, Goretta K C and Routbort J L 1989 J. Appl. Phys. 662079

Wong-Ng W, Roth R S, Swartzendruber L J, Bennet L. L, Chiang C K, Beech F and Hubbard C R 1987

Adv. Ceram. Mater. 2565 